On Avoiding Framing Effects in Experienced Decision Makers

\author{
Rocio Garcia-Retamero, $\mathrm{PhD},{ }^{1,2}$ and Mandeep K. Dhami, $\mathrm{PhD}^{3}$ \\ ${ }^{1}$ Department of Experimental Psychology, University of Granada (Spain)
}

${ }^{2}$ Center for Adaptive Behavior and Cognition, Max Planck Institute for Human Development, Berlin (Germany)

${ }^{3}$ School of Psychology, University of Surrey (England)

\begin{abstract}
Author Note
Rocio Garcia-Retamero, Ph.D. Center for Adaptive Behavior and Cognition, Max Planck Institute for Human Development, Lentzeallee 94, D-14195, Berlin, Email: rretamer@mpib-berlin.mpg.de. Facultad de Psicología, Universidad de Granada, Campus Universitario de Cartuja s/n, 18071 Granada, Spain, E-mail: rretamer@ugr.es. This experiment is part of the projects PSI2008-02019 funded by the Ministerio de Ciencia e Innovación (Spain), and PSI2011-22954 funded by the Ministerio de Economía y Competitividad Innovación (Spain).
\end{abstract}




\begin{abstract}
The present study aimed to (1) demonstrate the effect of positive-negative framing on experienced criminal justice decision makers, (2) examine the debiasing effect of visually structured risk messages, and (3) investigate whether risk perceptions mediate the debiasing effect of visual aids on decision making. In two phases, 60 senior police officers estimated the accuracy of a counter-terrorism technique in identifying whether a known terror suspect poses an imminent danger, and decided whether they would recommend the technique to policy makers. Officers also rated their confidence in this recommendation. When information about the effectiveness of the counter-terrorism technique was presented in a numerical format, officers' perceptions of accuracy and recommendation decisions were susceptible to the framing effect: The technique was perceived to be more accurate and was more likely to be recommended when its effectiveness was presented in a positive than negative frame. However, when the information was represented visually using icon arrays, there were no such framing effects. Finally, perceptions of accuracy mediated the debiasing effect of visual aids on recommendation decisions. We offer potential explanations for the debiasing effect of visual aids, and implications for communicating risk to experienced, professional decision makers.
\end{abstract}

Keywords: Framing Effect; Visual Aids; Police; Risk Perception; Decision Making; Terrorism 


\section{On Avoiding Framing Effects in Experienced Decision Makers}

The structure and content of risk messages have received considerable attention in the judgment and decision making literature. In the present paper, we consider how experienced professional decision makers can be biased by the framing of the content of risk messages, and we demonstrate the debiasing effects of restructuring such messages in a visual rather than numerical format.

How messages are framed can have a substantial impact on people's perceptions and behaviors (see Kuhberger, 1998; Levin, Schneider, \& Gaeth, 1998; Rothman \& Salovey, 1997). Following the work of Kahneman and Tversky (1979, 1982, 1984; see also McNeil, Pauker, Sox, \& Tversky, 1982; Tversky \& Kahneman, 1981), framing is defined as the presentation of two logically equivalent situations, where one is presented in positive or gain terms (e.g., saving lives or making money) and the other in negative or loss terms (e.g., deaths or losing money).

In their classic framing study called the "Asian disease problem," Tversky and Kahneman (1981) found that many people preferred a sure option of saving the lives of 200 (of 600) people threatened by the outbreak of a disease versus a risky option of taking a onethird chance of saving all 600 people when the options were described in positive terms (i.e., number of lives saved). However, when the options were described in negative terms (i.e., number of lives lost), many people selected the risky option of a one-third chance that nobody will die versus surely losing 400 people. Thus, despite the fact that the options were objectively equivalent (but see Mandel, 2001), people demonstrated risk aversion in the positive frame and risk seeking in the negative frame.

Framing effects appear to be ubiquitous. Previous research has shown that individuals who have low educational attainment or low cognitive ability demonstrate a stronger 
susceptibility to message framing than do highly educated individuals (Armstrong, Schwartz, Fitzgerald, Putt, \& Ubel, 2002) or those who have higher cognitive ability (Stanovich \& West, 1998). Similarly, individuals with low numeracy—who have difficulties grasping numerical concepts necessary for understanding risk communication (Cokely, Galesic, Schulz, Ghazal, \& Garcia-Retamero, 2012; Fagerlin, Ubel, Smith, \& Zikmund-Fisher, 2007; Galesic \& Garcia-Retamero, 2010)—are more susceptible to framing effects than those with high numeracy (Peters \& Levin, 2008; Peters et al., 2006).

Framing effects have also been observed in experienced professional decision makers in domains such as business (Loke \& Tan, 1992; Puto, Patton, \& King, 1985; Roszkowski \& Snelbecker, 1990), career choice (Hesketh, 2000), negotiation (Neale \& Bazerman, 1985; Neale \& Northcraft, 1986; Schurr, 1987), and health (Garcia-Retamero \& Galesic, 2012). However, there is a dearth of published research on the effect of framed messages in the criminal justice domain. Senior police officers make all sorts of decisions based on numerical information. For instance, they must decide on the best allocation of resources for the detection and investigation of crime based on data such as the volume of crime and its impact (e.g., number of victims, amount of money stolen, and quantity of drugs involved). Indeed, it is perhaps not difficult to imagine a situation where senior officers in the Metropolitan Police had to decide on whether or not to send officers to specific areas of London during the August 2011 riots based on the proportion of rioters that were (positive frame) or were not (negative frame) engaged in robbery, criminal damage, arson, and violence. The first aim of the present study is to investigate the effect of positive and negative framing in highly educated, experienced senior police officers.

In recognition of the potential problems associated with the biasing effects of framing, researchers have sought to develop debiasing techniques, primarily in research with undergraduate students. Three prominent techniques are stating the rationale for a choice 
(e.g., Kim, Goldstein, Hasher, \& Zacks, 2005; Miller \& Fagley, 1991; Sieck \& Yates, 1997), and describing the decision situation to another person before making the choice (Simon, Fagley, \& Halleran, 2004), which both promote more detailed thinking about the decision options. In addition, asking decision makers to list the advantages and disadvantages of the decision options, as well as providing a rationale for the option they plan to choose, has been shown to eliminate the framing effect (e.g., Almashat, Ayotte, Edelstein, \& Margrett, 2008). Finally, a study by Jou, Shanteau, and Harris (1996) showed that the effect of positive- and negative-framed messages can be eliminated when the two messages are related by a causal schema that illustrates that they are equivalent. The second aim of the present study is to examine another potential method that can reduce or eliminate the framing effect.

Specifically, we investigate the debiasing effect of presenting information in a visual format.

\section{Using Visual Aids to Reduce Framing Effects}

Researchers in the health and medical domains have studied the effectiveness of structuring risk messages in a visual rather than numerical format. Visual aids, such as icon arrays and bar graphs, have been proposed as potentially promising methods for improving the communication and understanding of risks (see e.g., Ancker, Senathirajah, Kukafka, \& Starren, 2006; Edwards, Elwyn, \& Mulley, 2002; Garcia-Retamero \& Galesic, in press; Lipkus, 2007; Schwartz, Woloshin, Black, \& Welch, 1997; Paling, 2003). Visual aids appear to facilitate information search, encoding and representation, including the potential advantages and disadvantages of risky behaviors (Galesic \& Garcia-Retamero, 2011).

Indeed, studies have shown that visual aids improve risk understanding (e.g., Galesic, Garcia-Retamero, \& Gigerenzer, 2009; Garcia-Retamero \& Galesic, 2010b; Lipkus, 2007; Lipkus \& Hollands, 1999; Paling, 2003), reduce errors induced by anecdotal narratives (Fagerlin, Wang, \& Ubel, 2005) and biases such as denominator neglect (e.g., GarciaRetamero \& Dhami, 2011; Garcia-Retamero \& Galesic, 2009; Garcia-Retamero, Galesic, \& 
Gigerenzer, 2010; Okan, Garcia-Retamero, Cokely, \& Maldonado, 2012), as well as increase risk avoidance (Schirillo \& Stone, 2005). Finally, risk information presented via visual aids is perceived to be easier to understand (Goodyear-Smith et al., 2008) and recall (Gaissmaier et al., 2011).

However, previous research on the usefulness of visual aids has often focused on people with low numeracy or cognitive capacity — who are more likely to be susceptible to biases in judgment and decision making (Reyna, Nelson, Han, \& Dieckmann, 2009). To illustrate, in a survey of probabilistic, national samples in two different countries (United States and Germany), Garcia-Retamero and Galesic (2010b) compared the effectiveness of adding different types of visual aids to numerical information about treatment risk reduction. Results showed large improvements in accuracy of risk understanding, regardless of which type of visual aids was used. In addition, visual aids were most useful for the participants who had low numeracy (see Garcia-Retamero \& Galesic, 2009; Garcia-Retamero et al., 2010 for similar results). It is unclear, however, whether visual aids would be as effective with the type of educated and experienced professional decision makers that we study here (i.e., senior police officers with a graduate level education).

In addition, to date, only few studies on visual aids have attempted to reduce the effect of framing on risk perceptions and decision making. For instance, Garcia-Retamero and Cokely (2011) showed that positive-framed messages were more effective in promoting disease prevention (e.g., condom use), whereas negative-framed messages were more effective for disease detection (e.g., screening for sexually transmitted diseases). Importantly, visual aids made both the positive- and negative-framed messages equally and highly effective in promoting prevention and detection (see also Garcia-Retamero \& Galesic, 2010a for similar results in compliance with surgical procedures and medical treatments). None of 
this research, however, has examined the debiasing effect of visual aids in experienced professional decisions makers as we do.

Lastly, although a large body of research has investigated the effectiveness of visual aids, relatively less research has examined the factors that can mediate their influence on decision making (Ancker et al., 2006). The study of Garcia-Retamero and Cokely (2011) showed that participants' beliefs and perceptions about engaging in detection and prevention behaviors were more positive when visual aids were added to the framed messages than when only numerical information was provided. These positive beliefs and perceptions strongly influenced participants' behavioral intentions, which in turn affected their actual behaviors. Hence cognitions can mediate the debiasing effect of visual aids on people's behavior. To the best of our knowledge, however, whether risk perceptions mediate the influence of visual aids on decision making has yet to be examined in professional decision makers. Investigating this issue is the final aim of the current research.

The Present Study

The present study had three main aims. The first was to demonstrate the effect of framing on experienced judgment and decision making in the criminal justice domain. In particular, we investigated the effect of positive-negative framed messages on senior police officers' perceptions of the accuracy of a counter-terrorism technique, their decisions about whether they would recommend the technique to policy makers, as well as their confidence in their decisions. The second aim was to examine the debiasing effect of visually—as opposed to numerically—structured risk messages. Finally, we aimed to investigate the processes that underlie the debiasing effect of visual aids on decision making. In particular, we explored whether police officers' perceptions of the accuracy of the technique mediated the effect of the visual aids on their recommendation decisions. 
In line with the past literature reviewed above, we hypothesized that experienced senior police officers would be susceptible to framing effects when making judgments and decisions about the counter-terrorism technique. We further hypothesized that visual aids would be effective in reducing this framing effect. Finally, we hypothesized that experienced senior police officers' perceptions of accuracy of the technique would mediate this effect.

$$
\text { Method }
$$

\section{Participants}

Sixty senior level police officers volunteered to participate in the study. They were all recruited from a professional graduate program at the University of Cambridge. The majority of the sample $(78.3 \%)$ was male. The sample had a mean age of $42.0(S D=9.4)$, and the majority of the sample $(76.7 \%)$ had a university education before attending the course at Cambridge. The average years of experience in the police force was $15.9(S D=10.2)$. Design and Materials

We employed a mixed design. Message frame (positive vs. negative) was manipulated within-subjects, and message format (numerical vs. visual) was manipulated betweensubjects.

The messages concerned a hypothetical counter-terrorism technique. We ensured that the positive- and negative-framed messages were objectively identical and that the same information was provided when the information was presented numerically and visually. When the information was provided numerically and in positive terms, participants were told: "When using this technique, 91 in 100 known terror suspects who organized and committed an attack were correctly identified as posing an imminent danger." When the information was provided numerically and in negative terms, participants were told: "When using this technique, 9 in 100 known terror suspects who organized and committed an attack were not correctly identified as posing an imminent danger." Figures 1a and $1 \mathrm{~b}$ describe the 
information when it was represented visually and in positive and negative terms, respectively. We used circles to represent the number of terror suspects because previous research (Gaissmaier et al., 2012; Stone, Yates, \& Parker, 1997) did not find differences in effects of arrays with faces compared to more abstract symbols. For half of the participants, black circles represented the terror suspects who were not correctly identified by the technique, and white circles were used to represent this number for the other half. In addition, half of the participants received visual aids with circles of the same color when the message was presented in positive and negative terms. For these participants, circles in the legend were of different color in the positive- and negative-framed messages (as in Figures 1a and 1b). The rest of the participants received visual aids with circles of swapped colors in the positive- and negative-framed messages (e.g., circles representing the terror suspects who were not correctly identified in white in the positive-framed message and in black in the negativeframed message). For these participants, circles in the legend were of the same color in the positive- and negative-framed messages.

\section{<Insert Figures 1a and 1b>}

The data was collected in two phases, conducted one week apart (see Levin, Gaeth, Schreiber, \& Lauriola, 2002 for a justification of the time interval between the two phases). Participants who received the information about the usefulness of the counter-terrorism technique in positive terms in the first phase of the study were provided with the information in negative terms in the second phase and vice versa. Participants who received the information numerically (or visually) in the first phase also received the information numerically (or visually) in the second phase.

\section{Measures}

In both phases, we measured participants' perceptions of the accuracy of the counterterrorism technique in identifying whether a known terror suspect poses an imminent danger, 
on a 5-point scale ranging from 1 (completely inaccurate) to 5 (completely accurate). Participants also decided whether they would recommend the technique to the Home Office by providing a binary yes/no response. Finally, participants rated their confidence in their recommendation on a 7-point scale ranging from 1 (not at all confident) to 7 (extremely confident).

In order to determine if our manipulation was successful, participants evaluated the tone of the message on 7-point scales ranging from -3 (mostly negative) to 3 (mostly positive). They also evaluated how informative the message was on 7-point scales ranging from 1 (not at all) to 7 (very much).

\section{Procedure}

All participants completed a two phase paper-and-pencil task. In the first phase, participants read some information describing a new (fictitious) counter-terrorism technique that predicts the likelihood of a known terror suspect committing a terrorist attack, and received empirical evidence on the usefulness of the technique when it was used in Canada. In the second phase, participants received data on the usefulness of the technique when it was used in the U.S. and answered all of the questions again (see Appendix). This represents a contemporary example of the policy-related decision making that police officers are involved in. The scenario was selected on the basis of its realism given that intelligence and police agencies in various countries have been developing profiling techniques for terrorists. An informal canvassing of officers and trainers in the Metropolitan police supported the representativeness of the scenario.

The task was self-administered in groups of 20. Participants also provided their demographic details (i.e., age, gender, education, and years of experience working as a police officer). There were no time constraints, but the task took approximately 10 minutes to complete in each phase. The order in which participants received the message frame (i.e., 
positive-framed message in the first phase and negative-framed message in the second phase or vice versa) was counterbalanced across participants.

\section{Results}

To test whether our manipulation was successful, we conducted analyses of variance (ANOVAs) with message frame (positive vs. negative) as a within-subjects factor and message format (numerical vs. visual) as a between-subjects factor on participants' evaluations of the tone and informativeness of the message. As required, there was a significant main effect of message frame on evaluation of the tone of the message, $F_{1,58}=9.85$, $p=.003, \eta^{2}=.14$. Participants who read the positive-framed message evaluated the tone of the message as significantly more positive $(M=1.7, S E M=.3)$ than those who read the negativeframed message $(M=.5, S E M=.3)$. The main effect of message format and the interaction between message frame and message format were not significant $(F<1)$. Also as required, there was no significant main effect of message frame or message format on evaluations of message informativeness. Neither was there any significant interaction effect between these factors $(F<1)$. Participants evaluated the message as equally informative when it was presented numerically $(M=5.3, S E M=.1)$ and visually $(M=5.2, S E M=.1)$. Below, we present the results by dependent measure (i.e., perceptions of accuracy, recommendation decisions, and confidence in decisions). Finally, we present the results of a mediational analysis.

\section{Perceptions of the Accuracy of the Counter-Terrorism Technique}

We examined the effect of message framing on perceptions of the accuracy of the counter-terrorism technique and the debiasing effect of the visual—as opposed to the numerical—message. First, we compared participants' perceptions of accuracy when the information about the effectiveness of the technique was provided in positive and negative terms in the visual and numerical message format conditions. Second, we compared the 
percentage of participants with consistent perceptions (i.e., with equal perceptions of accuracy under the positive and negative message frames).

The ANOVA with message frame (positive vs. negative) as a within-subjects factor and message format (numerical vs. visual) as a between-subjects factor on perceptions of accuracy showed a significant main effect of message frame, $F_{1,58}=21.64, p=.0001, \eta^{2}=.23{ }^{1}$ This effect was qualified by an interaction between message frame and message format, $F_{1,58}=15.03, p=.0003, \eta^{2}=.16$. The main effect of message format was not reliable $(F<1)$. When information about the effectiveness of the technique was provided numerically, participants perceived the technique as more accurate under the positive than the negative frame ( $p=.0002$; see Figure 2). In contrast, when the information about the technique's effectiveness was represented visually, participants perceived the technique as equally accurate under the positive and the negative frame $(p=.424)$. Thus, the framing effect was more prominent in the numerical than the visual message format condition. Consistent with these results, in the visual message format condition more participants ( $M=90 \%, S E M=5.6)$ perceived the technique as equally accurate when the information about accuracy was framed in positive and negative terms as compared to the numerical message format condition $\left(M=37 \%, S E M=8.9, \chi^{2}(1)=18.37, p=.0001, d=1.78\right)$.

\section{<Insert Figure 2>}

\section{Recommendation Decisions}

We examined the effect of message framing and visual aids on participants' decisions to recommend the counter-terrorism technique. First, we compared the percentage of participants who recommended the technique when information about its effectiveness was provided in positive and negative terms in the visual and numerical message format conditions. Second, we compared the percentage of participants who were consistent in their 
decisions (i.e., who made similar recommendations when the information was framed in positive and negative terms).

As Figure 3 shows, more participants recommended the technique when information about effectiveness was provided numerically and framed positively than negatively $\left(\chi^{2}(1)=15.43, p=.0001, d=.89\right)$. In contrast, when information about the technique's effectiveness was represented visually, the percentage of participants who recommended the technique was similar under the positive and negative frames $\left(\chi^{2}(1)=.07, p=.79, d=.11\right)$. In line with these results, more participants were consistent in their decisions when the technique's effectiveness was presented visually $(M=90 \%, S E M=5.6)$ than numerically $\left(M=43 \%, S E M=9.2, \chi^{2}(1)=14.70, p=.0001, d=1.56\right)$.

$<$ Insert Figure 3>

\section{Confidence in Recommendation Decisions}

We examined the effect of message framing and visual aids on participants' confidence in their decisions to recommend the counter-terrorism technique. First, we compared confidence when the information about the technique's effectiveness was provided in positive and negative terms in the visual and numerical message format conditions.

Second, we compared the percentage of participants who were equally confident in their decisions when the technique's effectiveness was expressed in positive and negative terms in such conditions.

The ANOVA with message frame (positive vs. negative) as a within-subjects factor and message format (numerical vs. visual) as a between-subjects factor on confidence in decisions showed a significant main effect of message format, $F_{1,58}=10.51, p=.002, \eta^{2}=.15$. There was no significant effect of message frame, and no significant interaction effect $(F<1)$. Participants were more confident in their decisions about recommending the technique when the information was presented visually $(M=5.7, S E M=.1)$ than numerically $(M=4.7, S E M=.2)$. 
In addition, more participants were equally confident when the technique's effectiveness was expressed in positive and negative terms in the visual $(M=80 \%, S E M=7.4)$ than in the numerical condition $\left(M=53 \%, S E M=9.3, \chi^{2}(1)=4.80, p=.029 ; d=.67\right)$.

\section{Mediational Analyses}

Finally, we investigated whether consistency in perceptions of the accuracy of the technique mediates the effect of message format on consistency in recommendation decisions. For there to be mediation, message format should influence consistency in decisions, and the potential mediator (i.e., consistency in perceptions of accuracy) must be both affected by message format and related to consistency in decisions (see Baron \& Kenny, 1986).

In line with the results reported above, regression analyses showed that message format influenced both consistency in perceptions of accuracy $\left(\beta=.55, t_{58}=5.06, p=.001\right)$ and consistency in decisions $\left(\beta=.49, t_{58}=4.34, p=.001\right)$. More participants provided equal estimates of the accuracy of the technique and made consistent decisions after receiving the visual positive- and negative-framed messages as compared to receiving the same framed messages numerically. In addition, consistency in perceptions of accuracy influenced consistency in decisions $\left(\beta=.78, t_{58}=9.57, p=.001\right.$; see Figure 4$)$. Participants with equal estimates of the accuracy of the technique under the positive and negative frames often made consistent recommendation decisions. Finally, when consistency in perceptions of accuracy was included in the regression analysis, the effect of message frame on consistency of recommendation decisions was reduced and no longer significant $\left(\beta=.09, t_{57}=.91, p=.37\right)$. The result of the Sobel test ${ }^{2}$ suggests that consistency in perceptions of accuracy fully mediated the influence of message frame on consistency in decisions, $z=4.79, p=.001$. 


\section{Discussion}

We examined the effect of message frame and message format on experienced senior police officers' perceptions of the accuracy of a hypothetical counter-terrorism technique in identifying whether a known terror suspect poses an imminent danger, their decisions about whether to recommend the technique to the Home Office, and their confidence in their recommendations. Our results have several theoretical and practical implications.

First, consistent with our hypothesis and past literature on framing effects (e.g., Kuhberger, 1998; Levin et al., 1998; Rothman \& Salovey, 1997), we found that experienced, professionals are susceptible to the framing effect, as are naïve individuals. In particular, a greater proportion of senior police officers judged the counter-terrorism technique as effective and more would recommend adopting the technique when the accuracy of the technique was expressed as the percentage of correctly identified terror suspects (i.e., positive-framed message) rather than as the percentage of incorrectly identified suspects (i.e., negative-framed message). Thus, our results extend past research on framing effects to another domain (i.e., criminal justice and security) and to another population (i.e., experienced professionals). Our research also contributes to the small body of research on terrorism and risk perceptions. In fact, there is a dearth of published research on the effect of framed messages on risk perceptions and decision making in the terrorism context (HaiderMarkel, Joslyn, \& Al-Baghal, 2006; Montiel \& Shah, 2008), and most of the past work on terror risks has involved lay people or convenience samples of undergraduates (see Gibson, Lemyre, Clément, Markon, \& Lee, 2007; Mandel, 2005; Spillman, 2003; Sunstein, 2003; see Fischhoff, Gonzalez, Lerner, \& Small 2005; Fischhoff, Gonzalez, Small, \& Lerner, 2003 for exceptions). In addition, our study demonstrated the framing effect using a within-subjects design, whereas most past research on framing effects has used a between-subjects design. 
Second, as predicted, we found that framing effect was eliminated when the message was communicated in a visual rather than numerical format. Indeed, when information about the counter-terrorism technique's effectiveness was represented visually via icon arrays, a greater proportion of senior police officers judged the technique as equally accurate under positive and negative frames. Similarly, a greater proportion of participants were consistent in their decisions (i.e., made similar recommendations under positive and negative frames) under the visual as opposed to numerical format. Participants were also significantly more confident in their recommendations under the visual than numerical format. These results are robust as they persisted after controlling for participants' sex, age, education, and years of experience. Thus, our study demonstrates a fairly simple method for reducing framing effects. Our results also extend our own and others' past research on visual aids (Garcia-Retamero \& Galesic, in press; Lipkus, 2007; Paling, 2003) by demonstrating the effectiveness of such aids in improving risk communication and understanding in a new domain and among experienced, professional decision makers.

Third, of note, the present study reveals some key aspects of the cognitive processes that underlie the impact of visual aids on decisions. In particular, the results of the mediational analysis indicated that the influence of visual aids on consistency in decisions to recommend the technique was fully mediated by consistency in perceptions of the accuracy of the technique. These results are compatible with published research documenting the important role of risk perceptions in shaping behaviours in the health (see Floyd, PrenticeDunn, \& Rogers, 2000; Milne, Sheeran, \& Orbell, 2000) and financial domains (Simon, Houghton, \& Aquino, 1999; Sitkin \& Weingart, 1995). The present study extends the past literature by providing evidence from experienced decision makers in the criminal justice domain. 
A possible explanation for the differential impact of presenting risk information in a visual versus numerical format is that visual aids might have encouraged more precise, quantitative processing of the numerical information (Garcia-Retamero \& Galesic, in press). ${ }^{3}$ Previous research also suggests that individuals who more elaboratively encode and thoroughly process information during learning and risky decision making (Cokely \& Kelley, 2009; Cokely, Kelley, \& Gilchrist, 2006) also tend to be less susceptible to the effects of message framing (Stanovich \& West, 1998; but see also Corbin, McElroy, \& Black, 2010 for boundary conditions). Visual aids may also have other properties that facilitate information comprehension (e.g., there might be a more transparent, fast, and memorable representation of risks; Galesic \& Garcia-Retamero, 2011; Gigerenzer, Gaissmaier, Kurz-Milcke, Schwartz, $\&$ Woloshin, 2007). Our ongoing research is currently using cognitive process tracing techniques (e.g., eye-tracking, memory assessments, reaction time analyses, and protocol analyses) to assess the validity of this theoretical account (Okan, Galesic, \& GarciaRetamero, 2012; Okan, Garcia-Retamero, Galesic, \& Cokely, 2012; see Garcia-Retamero, Okan, \& Cokely, 2012 for a review).

In sum, our results support the notion that problems in communicating risks do not simply result because biases prevent good decision making (Garcia-Retamero, Hoffrage, \& Dieckmann, 2006; Garcia-Retamero \& Rieskamp, 2009). In contrast, errors occur because inappropriate information formats may complicate and mislead decision makers (Gigerenzer \& Edwards, 2003; Gigerenzer et al., 2007). Using transparent formats to communicate risk information enhances comprehension and recall, and can help people to make better decisions. Importantly, unlike other methods proposed to improve decision making, visual aids do not put the onus on the decision maker to engage in some preventive measure. Visual aids are external to the individual and focus on improving his/her task environment. 


\section{References}

Almashat, S., Ayotte, B., Edelstein, B., \& Margrett, J. (2008). Framing effect debiasing in medical decision making. Patient Education and Counseling, 71, 102-107.

Armstrong, K., Schwartz, J. S., Fitzgerald, G., Putt, M., \& Ubel, P. A. (2002). Effect of framing as gain versus loss on understanding and hypothetical treatment choices: Survival and mortality curves. Medical Decision Making, 22, 76-83.

Ancker, J. S., Senathirajah, Y., Kukafka, R., \& Starren, J. B. (2006). Design features of graphs in health risk communication: A systematic review. Journal of the American Medical Informatics Association, 13, 608-618.

Baron, R. M., \& Kenny, D. A. (1986). The moderator-mediator variable distinction in social psychological research: Conceptual, strategic, and statistical consideration. Journal of Personality and Social Psychology, 51, 1173-1182.

Cokely, E.T., Galesic, M. Schulz, E., Ghazal, S., \& Garcia-Retamero, R. (2012). Measuring risk literacy: The Berlin Numeracy Test. Judgment and Decision Making, 7, 25-47.

Cokely, E. T., \& Kelley, C.M. (2009). Cognitive abilities and superior decision making under risk: A protocol analysis and process model evaluation. Judgment and Decision Making, 4, 20-33.

Cokely, E. T., Kelley, C. M., \& Gilchrist, A. H. (2006). Sources of individual differences in working memory: Contributions of strategy to capacity. Psychonomic Bulletin \& Review, 13, 991-997.

Corbin, J., McElroy, T., \& Black, C. (2010). Memory reflected in our decisions: Higher working memory capacity predicts greater bias in risky choice. Judgment and Decision Making, 5, 110-115.

Edwards, A., Elwyn, G., \& Mulley, A. (2002). Explaining risks: Turning numerical data into meaningful pictures. British Medical Journal, 324, 827-830. 
Fagerlin, A., Ubel, P. A., Smith, D. M., \& Zikmund-Fisher, B. J. (2007). Making numbers matter: Present and future research in risk communication. American Journal of Health Behavior, 31, 47-56.

Fagerlin, A., Wang, C., \& Ubel, P. A. (2005). Reducing the influence of anecdotal reasoning on people's health care decisions: Is a picture worth a thousand statistics? Medical Decision Making, 25, 398-405.

Fischhoff, B., Gonzalez, R. M., Lerner, J. S., \& Small, D. A. (2005). Evolving judgments of terror risks: Foresight, hindsight, and emotion. Journal of Experimental Psychology: Applied, 11, 124-139.

Fischhoff, B., Gonzalez, R. M., Small, D. A., \& Lerner, J. S. (2003). Evaluating the success of terror risk communications. Biosecurity and Bioterrorism: Biodefense Strategy, Practice, and Science, 1, 255-258.

Floyd, D. L., Prentice-Dunn, S., \& Rogers, R. W. (2000). A meta-analysis of research on protection motivation theory. Journal of Applied Social Psychology, 30, 407-429.

Gaissmaier, W., Wegwarth, O., Skopec, D., Müller, A., Broschinski, S., \& Politi, M. C. (2012). Numbers can be worth a thousand pictures: Individual differences in understanding graphical and numerical representations of health-related information. Health Psychology, 31, 286-296.

Galesic, M., \& Garcia-Retamero, R. (2010). Statistical numeracy for health: A cross-cultural comparison with probabilistic national samples. Archives of Internal Medicine, 170, $462-468$.

Galesic, M., \& Garcia-Retamero, R. (2011). Graph literacy: A cross-cultural comparison. Medical Decision Making, 31, 444-457. 
Galesic, M., Garcia-Retamero, R., \& Gigerenzer, G. (2009). Using icon arrays to communicate medical risks: Overcoming low numeracy. Health Psychology, 28, 210-216.

Garcia-Retamero, R., \& Cokely, E. T. (2011). Effective communication of risks to young adults: Using message framing and visual aids to increase condom use and STD screening. Journal of Experimental Psychology: Applied, 17, 270-287.

Garcia-Retamero, R., \& Dhami, M. K. (2011). Pictures speak louder than numbers: On communicating medical risks to immigrants with limited non-native language proficiency. Health Expectations, 14, 46-57.

Garcia-Retamero, R., \& Galesic, M. (2009). Communicating treatment risk reduction to people with low numeracy skills: A cross-cultural comparison. American Journal of Public Health, 99, 2196-2202.

Garcia-Retamero, R., \& Galesic, M. (2010a). How to reduce the effect of framing on messages about health. Journal of General Internal Medicine, 25, 1323-1329.

Garcia-Retamero, R., \& Galesic, M. (2010b). Who profits from visual aids: Overcoming challenges in people's understanding of risks. Social Science \& Medicine, 70, $1019-1025$.

Garcia-Retamero, R., \& Galesic, M. (2012). Doc, what would you do if you were me? On self-other discrepancies in medical decision making. Journal of Experimental Psychology: Applied, 18, 38-51.

Garcia-Retamero, R., \& Galesic, M. (in press). Transparent communication of health risks: Overcoming cultural differences. New York, NY: Springer.

Garcia-Retamero, R., Galesic, M., \& Gigerenzer, G. (2010). Do icon arrays help reduce denominator neglect? Medical Decision Making, 30, 672-684. 
Garcia-Retamero, R., Hoffrage, U., \& Dieckmann, A. (2007). When one cue is not enough: Combining fast and frugal heuristics with compound cue processing. Quarterly Journal of Experimental Psychology, 60, 117-1215.

Garcia-Retamero, R., Okan, Y., \& Cokely, E. T. (2012). Using visual aids to improve communication of risks about health: A review. The Scientific World Journal. Article ID 562637. Doi:10.1100/2012/562637.

Garcia-Retamero, R., \& Rieskamp, J. (2009). Do people treat missing information adaptively when making inferences? Quarterly Journal of Experimental Psychology, 62, 1991-2013.

Gibson, S., Lemyre, L., Clément, M., Markon, M. L., \& Lee, J. E. C. (2007). Terrorism threats and preparedness in Canada: The perspective of the Canadian public. Biosecurity and Bioterrorism: Biodefense Strategy, Practice, and Science, 5, 134-144.

Gigerenzer, G., \& Edwards, A. (2003). Simple tools for understanding risks: From innumeracy to insight. British Medical Journal, 327, 741-744.

Gigerenzer, G., Gaissmaier, W., Kurz-Milcke, E., Schwartz, L. M., \& Woloshin, S. (2007). Helping doctors and patients make sense of health statistics. Psychological Science in the Public Interest, 8, 53-96.

Goodyear-Smith, F., Arroll, B., Chan, L., Jackson, R., Wells, S., \& Kenealy, T. (2008). Patients prefer pictures to numbers to express cardiovascular benefit from treatment. Annals of Family Medicine, 6, 213-217.

Haider-Markel, D. P., Joslyn, M. R., \& Al-Baghal, M. T. (2006). Can we frame the terrorist threat? Issue frames, the perception of threat, and opinions on counterterrorism policies. Terrorism \& Political Violence, 18, 545-559.

Hesketh, B. (2000). Time perspective in career-related choices: Applications of timediscounting principles. Journal of Vocational Behavior, 57, 62-84. 
Jou, J., Shanteau, J., \& Harris, R. J. (1996). An information processing view of framing effects: The role of causal schemas in decision making. Memory \& Cognition, 24, 115.

Kahneman, D., \& Tversky, A. (1979). Prospect theory: An analysis of decision making under risk. Econometrica, 6, 621-630.

Kahneman, D., \& Tversky, A. (1982). The psychology of preferences. Scientific American, $46,160-173$.

Kahneman, D., \& Tversky, A. (1984). Choices, values, and frames. American Psychologist, $39,341-350$.

Kim, S., Goldstein, D., Hasher, L., \& Zacks, R. T. (2005). Framing effects in younger and older adults. Journal of Gerontology: Psychological Sciences, 60B, 215-P218.

Kuhberger, A. (1998). The influence of framing on risky decisions: A meta-analysis. Organizational Behavior and Human Decision Processes, 75, 23-55.

Levin, I. P., Schneider, S. L., \& Gaeth, G. J. (1998). All frames are not created equal: A typology and critical analysis of framing effects. Organization Behavior and Human Decision Processes, 76, 149-188.

Levin, I. P., Gaeth, G. J., Schreiber, J., \& Lauriola, M. (2002). A new look at framing effects: Distribution of effect sizes, individual differences, and independence of types of effects. Organizational Behavior and Human Decision Processes, 88, 411-429.

Lipkus, I. M. (2007). Numeric, verbal, and visual formats of conveying health risks: Suggested best practices and future recommendations. Medical Decision Making, 27, 696-713.

Lipkus, I. M., \& Hollands, J. G. (1999). The visual communication of risk. Journal of the National Cancer Institute Monographs, 25, 149-163. 
Loke, W. H., \& Tan, K. F. (1992). Effects of framing and missing information in expert and novice judgment. Bulletin of the Psychonomic Society, 30, 187-190.

Mandel, D. R. (2001). Gain-loss framing and choice: Separating outcome formulations from descriptor formulations. Organizational Behavior and Human Decision Processes, 85, $56-76$.

Mandel, D. R. (2005). Are risk assessments of a terrorist attack coherent? Journal of Experimental Psychology: Applied, 11, 277-288.

McNeil, B. J., Pauker, S. G., Sox, H. C., \& Tversky, A. (1982). On the elicitation of preferences for alternative therapies. New England Journal of Medicine, 306, 12591262.

Milne, S., Sheeran, P., \& Orbell, S. (2000). Prediction and intervention in health-related behavior: A meta-analytic review of protection motivation theory. Journal of Applied Social Psychology, 30, 106-143.

Miller, P. M., \& Fagley, N. S. (1991). The effects of framing, problem variations, and providing rationale on choice. Personality and Social Psychology Bulletin, 17, 517522.

Montiel, C. J., \& Shah, A. A. (2008). Effects of political framing and perceiver's social position on trait attributions of a terrorist/freedom fighter. Journal of Language and Social Psychology, 27, 266-275.

Neale, M. A., \& Bazerman, M. (1985). Perspectives for understanding negotiation: Viewing negotiations as a judgmental process. Journal of Conflict Resolution, 29, 33-55.

Neale, M. A., \& Northcraft, G. B. (1986). Experts, amateurs, and refrigerators: Comparing expert and amateur negotiators in a novel task. Organizational Behavior and Human Decision Processes, 38, 305-317. 
Okan, Y., Galesic, M., \& Garcia-Retamero, R. (2012). How people with low and high graph literacy process graphs: An eye-tracking study. Manuscript in preparation.

Okan, Y., Garcia-Retamero, R., Cokely, E. T., \& Maldonado, A. (2012). Individual differences in graph literacy: Overcoming denominator neglect in risk comprehension. The Journal of Behavioral Decision Making, 25, 390-401.

Okan, Y., Garcia-Retamero, R., Galesic, M., \& Cokely, E. (2012). When higher bars are not larger quantities: On individual differences in the use of spatial information in graph comprehension. Spatial Cognition and Computation, 12, 195-218.

Paling, J. (2003). Strategies to help patients understand risks. British Medical Journal, 327, $745-748$.

Peters, E., \& Levin I. P. (2008). Dissecting the risky-choice framing effect: Numeracy as an individual-difference factor in weighting risky and riskless options. Judgment and Decision Making, 3, 435-448.

Peters, E., Västfjäll, D., Slovic, P., Mertz, C. K., Mazzocco, K., \& Dickert, S. (2006). Numeracy and decision making. Psychological Science, 17, 407-413.

Puto, C. P., Patton, W. E., \& King, R. H. (1985). Risk handling strategies in industrial vendor situation decisions. Journal of Marketing, 49, 89-98.

Reyna, V. R., Nelson, W. L., Han, P., \& Dieckmann, N. F. (2009). How numeracy influences risk comprehension and medical decision making. Psychological Bulletin, 135, 943-973.

Roszkowski, M. J., \& Snelbecker, G. E. (1990). Effects of “framing” on measures of risk tolerance: Financial planners are not immune. The Journal of Behavioral Economics, $19,237-246$.

Rothman, A. J., \& Salovey, P. (1997). Shaping perceptions to motivate healthy behavior: The role of message framing. Psychological Review, 121, 3-19. 
Schirillo, J. A., \& Stone, E. R. (2005). The greater ability of graphical versus numerical displays to increase risk avoidance involves a common mechanism. Risk Analysis, 25, $555-566$.

Schurr, P. H. (1987). Effects of gain and loss decision frames on risky purchase negotiations. Journal of Applied Psychology, 72, 351-358.

Schwartz, L. M., Woloshin, S., Black, W. C., \& Welch, H. G. (1997). The role of numeracy in understanding the benefit of screening mammography. Annals of Internal Medicine, 127, 966-972.

Sieck, W., \& Yates, J. F. (1997). Exposition effects on decision making. Organizational Behavior and Human Decision Processes, 70, 207-219.

Simon, A. F., Fagley, N. S., \& Halleran, J. G. (2004). Decision framing: Moderating effects of individual differences and cognitive processing. Journal of Behavioral Decision Making, 17, 77-93.

Simon, M., Houghton, S. M., \& Aquino, K. (1999). Cognitive biases, risk perception, and venture formation: How individuals decide to start companies. Journal of Business Venturing, 15, 113-134.

Sitkin, S. B. \& Weingart, L. R. (1995). Determinants of risky decision-making behavior: A test of the mediating role of risk perceptions and propensity. Academy of Management Journal, 38, 1573-1592.

Sobel, M. E. (1982). Asymptotic confidence intervals for indirect effects in structural models. In S. Leinhardt (Ed.), Sociological methodology (pp. 209-312). San Francisco: Jossey-Bass.

Spillman, D. M. (2003). Do American citizens consider their food supply at risk for terrorism attack? Psychological Reports, 93, 1159-1160. 
Stanovich, K. E., \& West, R. F. (1998). Individual differences in framing and conjunction effects. Thinking and Reasoning, 4, 289-317.

Stone, E. R., Yates, J. F., \& Parker, A. M. (1997). Effects of numerical and graphical displays on professed risk-taking behavior. Journal of Experimental Psychology: Applied, 3, $243-256$.

Sunstein, C. R. (2003). Terrorism and probability neglect. The Journal of Risk and Uncertainty, 26, 121-136.

Tversky, A., \& Kahneman, D. (1981). The framing of decisions and the psychology of choice. Science, 211, 453-458. 


\section{Footnote}

1. Neither these nor the rest of the analyses including the interaction between message frame and message format were influenced by the order in which participants received the framed messages (i.e., in positive terms first vs. in negative terms first) or the color of the circles in the visual aids (i.e., white vs. black, and same vs. swapped in the positive- and negative-framed messages). The inclusion of participants' sex, age, level of education, and years of experience in the analyses either as independent variables or as covariates did not systematically influence perceptions of accuracy, recommendation decisions, or confidence in decisions $(F s<1)$.

2. The Sobel test (see Sobel, 1982) indicates whether the indirect effect of the independent variable through the mediator to the dependent variable is significant.

3. A critic could argue that our results are due to the fact that participants in the visual aids conditions received similar information about the counter-terrorism when the risk information was framed in positive and negative terms. This might help participants infer that the percentage of terror suspect is the same in the two conditions. To exclude this alternative explanation of our results, we conducted a pilot study ( $n=64$ undergraduate students from the University of Granada, Spain). Participants in the study were randomly assigned to one of four conditions. In two conditions, the information was represented visually in positive and negative terms as we reported in the methods section. In the other two conditions, the information was provided numerically and both in positive and negative terms. In one of these conditions, participants received the information framed in positive terms first; in the other condition, they received the information framed in negative terms first. In line with our previous findings, when information was provided numerically, the effect of framing was reliable ( $p=.001)$. Participants who received the numerical information framed in positive terms first perceived the technique as more accurate $(3.40, S E M=.12)$ than those who 
received the numerical information framed in negative terms first (3.01, SEM=.71). In contrast, when the information about the technique was presented visually, participants perceived the technique as equally accurate when framed in positive and negative terms $(p=.624)$. We can then conclude that visual aids are highly effective for eliminating the framing effect because they might have encouraged more quantitative processing of the numerical information. 


\section{Appendix}

Participants read the following introductory statement in the first phase of the study: "In recent years, the Home Office has substantially increased counter-terrorism efforts. But the threat of attack remains real and constant. Imagine that the Home Office was considering adopting a technique based on offender profiling developed by Canadian intelligence officers, which predicts the likelihood of a known terror suspect committing a terrorist attack. The Canadians have provided the Home Office with data on the usefulness of the technique, and you are on an advisory panel to determine if it should be adopted in the U.K. Below is the summary of the Canadian data when using this technique. Please read this information and answer the questions that follow."

In the second phase of the study, participants read the following information: "If you remember, last week you imagined that the Home Office was considering adopting a technique based on offender profiling developed by Canadian intelligence officers, which predicts the likelihood of a known terror suspect committing a terrorist attack. This time, imagine that the Canadians have provided the Home Office with data on the usefulness of the technique when it was used in the U.S. You are again on an advisory panel to determine if it should be adopted in the U.K. Below is the summary of the U.S. data. Please read this information and answer the questions that follow." 


\section{Figure Captions}

Figure 1. Icon arrays representing visually the information about the usefulness of the technique framed in positive (Figure 1a) and negative terms (Figure 1b).

Figure 2. Average perceptions of the accuracy of the technique as a function of message frame and message format. Error bars represent one standard error.

Figure 3. Percentage of participants who would recommend the Home Office adopting the technique by message frame and message format. Error bars represent one standard error.

Figure 4. Path analysis of the effect of message format on consistency in recommendation decisions, and the mediational effect of consistency in perceptions of accuracy. Note: Standardized coefficients and the coefficient after controlling for consistency in perceptions of accuracy in parenthesis are shown $* p<.001$. 
Figure 1a

Terror suspects who organized and committed an attack

O०००००००००

0000000000

0000000000

0000000000

0000000000

0000000000

0000000000

0000000000

Terror suspects who were correctly

identified as posing an

imminent danger when

using the technique

0000000000

0000000000

Figure 1b

Terror suspects who organized

and committed an attack

0000000000

0000000000

0000000000

0000000000

0000000000

0000000000

0000000000

0000000000

- Terror suspects who were not correctly

identified as posing an

imminent danger when

0000000000

using the technique 
Figure 2

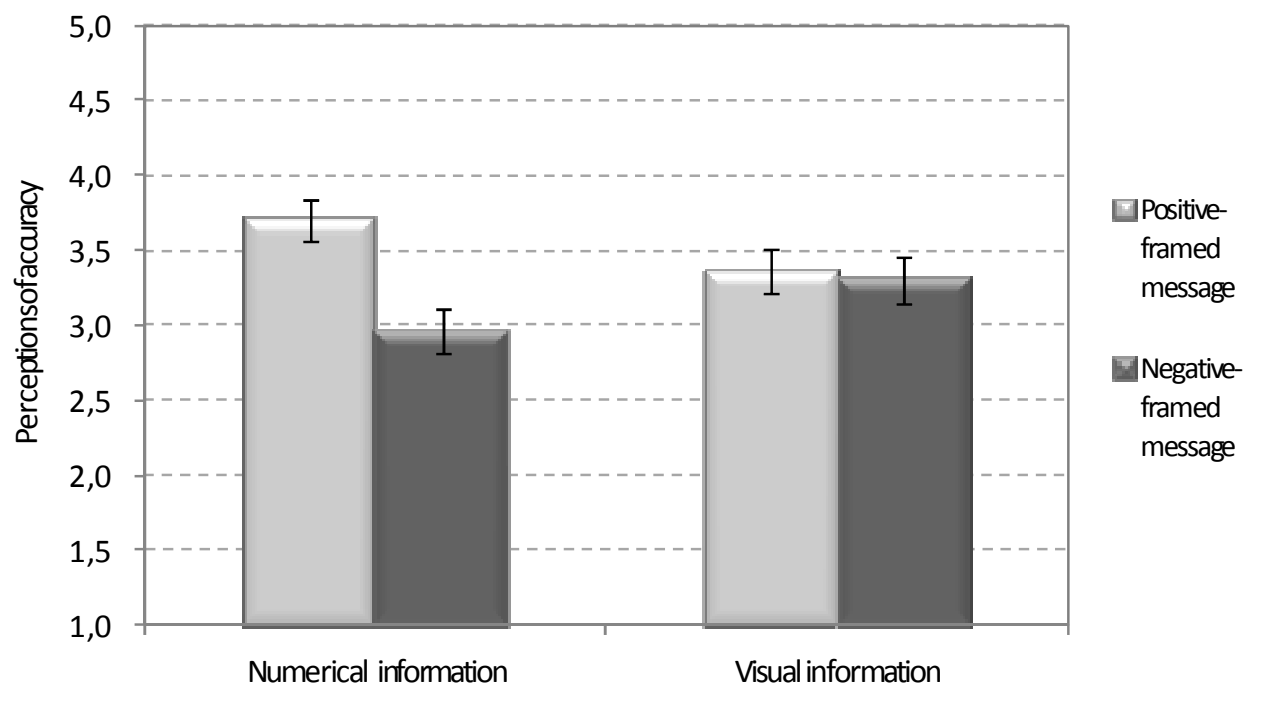


Figure 3

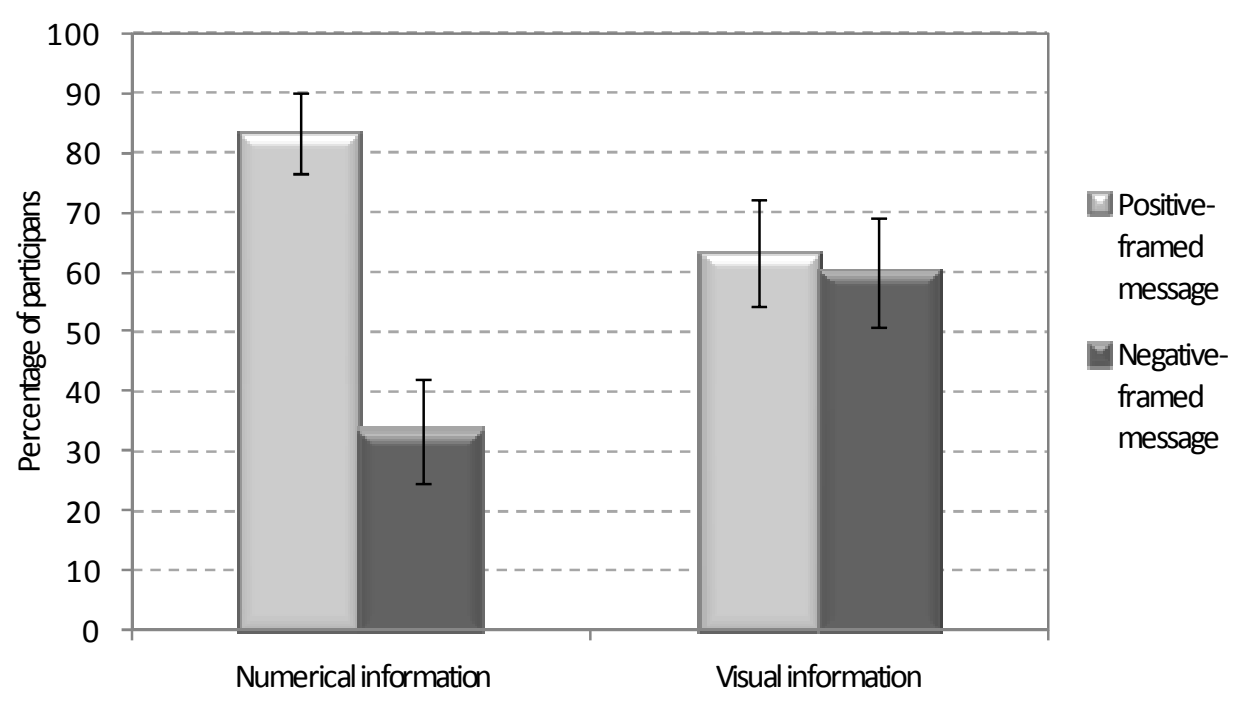


Figure 4

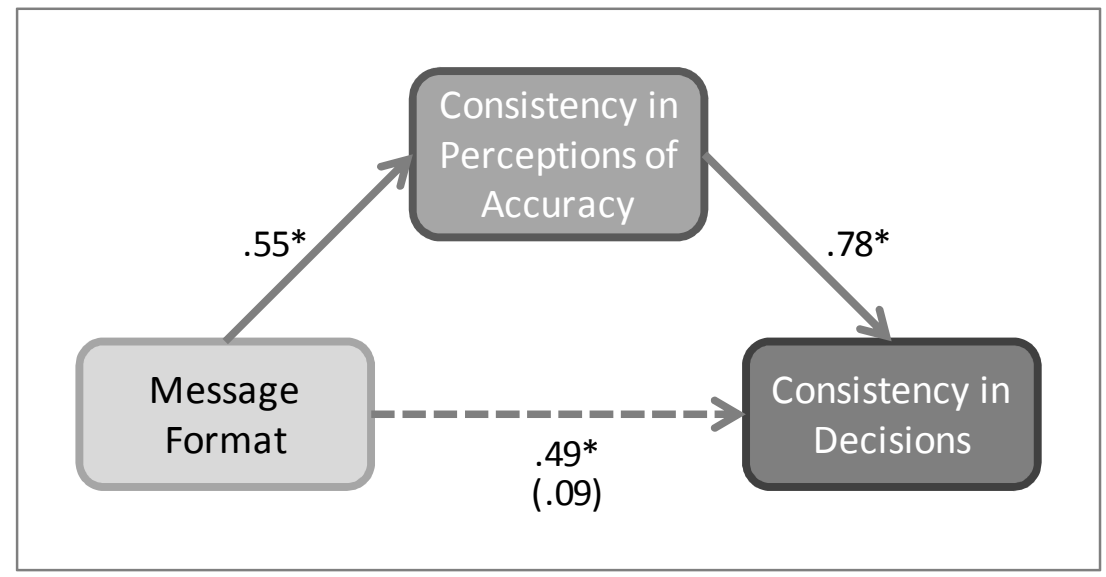

